\title{
Fluorescence and nonphotochemical quenching responses to simulated vertical mixing in the marine diatom Thalassiosira weissflogii
}

\author{
Allen J. Milligan*, Uriel A. Aparicio, Michael J. Behrenfeld \\ Department of Botany and Plant Pathology, Oregon State University, Corvallis, Oregon 97331, USA
}

\begin{abstract}
The fluorescence signal emitted from phytoplankton exposed to natural sunlight has been considered a potentially useful tool to examine phytoplankton physiology from in situ radiometers and satellites, but variability in the fluorescence signal is confounded by nonphotochemical quenching (NPQ). This pathway dissipates excitation energy as heat rather than fluorescence. It is necessary to first correct for this NPQ signal in order to extract physiological information, such as rates or nutrient stresses. Here we examine the fluorescence-irradiance response and NPQ in a marine diatom grown under simulated vertical mixing. Contrary to previous studies, we find that low-light-acclimated cultures express greater NPQ than high-lightacclimated cultures. Our results differ from previous studies because we employ realistic vertical mixing, rather than constant light conditions. We also find that fluorescence yields do not saturate at high-light levels. This observation impacts how we might apply NPQ corrections to radiometer and satellite data.
\end{abstract}

KEY WORDS: Fluorescence $\cdot$ Non-photochemical quenching $\cdot$ Fluctuating light $\cdot$ Diatom

Resale or republication not permitted without written consent of the publisher

\section{INTRODUCTION}

Oxygenic photosynthesis involves light harvesting to form chemical energy through the action of photosystem II (PSII) and photosystem I (PSI). A small fraction $(\sim 2 \%)$ of the solar energy absorbed by phytoplankton for photosynthesis is re-radiated by chlorophyll pigments as fluorescence. Both photosystems contribute to total cellular chlorophyll concentration, but in vivo fluorescence is dominated by emissions from antennae pigments at the core of PSII (Krause \& Weis 1991). Under natural sunlight conditions, chlorophyll fluorescence can be detected in the subsurface- and above-surface upwelling radiance spectrum (Morel \& Prieur 1977, Neville \& Gower 1977). This sun-induced natural fluorescence feature has been proposed as a tool for deriving phytoplankton photosynthetic rates (Kiefer 1973, Falkowski \& Kiefer 1985, Kiefer et al. 1989) and physiological vari- ability (Letelier et al. 1997, Morrison 2003, Schallenberg et al. 2008).

A wide range of physiological factors influence fluorescence, but the most important of these are photochemical quenching (qP) and non-photochemical quenching (NPQ). Photochemical quenching is associated with charge separation in the PSII reaction center, while NPQ is a protective response to high-light exposure that is broadly expressed in phytoplankton (Niyogi et al. 1997, Lavaud et al. 2007, Miloslavina et al. 2009). NPQ reduces fluorescence and encompasses a variety of physiological mechanisms that dissipate excess absorbed light energy as heat before it reaches the core of PSII. One mechanism of NPQ is a rapid response (seconds) to super-saturating light that is dependent on a thylakoid proton gradient and photoprotective pigments (xanthophylls) (Holt et al. 2004). This form of NPQ is referred to as $\mathrm{qE}$. In diatoms, $\mathrm{qE}$ is likely achieved through conformational changes in 
PSII and conversion of diadinoxanthin to diatoxanthin (a fluorescence quencher) in a single de-epoxidation reaction (Lavaud et al. 2002, Lavaud \& Kroth 2006, Grouneva et al. 2009).

A second form of NPQ is a rebalancing of light energy between the 2 photosystems and involves the physical movement of light harvesting antennae complexes from PSII to PSI. This process, termed a state transition or $\mathrm{qT}$, functions on longer time scales (minutes) than $\mathrm{qE}$ and allows movement of a pool of chlorophyll from fluorescence-emitting PSII to weakly-fluorescent PSI. There is no direct evidence for state transitions in diatoms (Owens 1986, Ting \& Owens 1994, Miloslavina et al. 2009). A final form of NPQ involves quenching at the PSII reaction center and can be associated with either protein damage or reversible down-regulation of PSII. We distinguish the former form as qI (I for inhibition; Holt et al. 2004) and the later, reversible form as qRC (RC for reaction center). qRC is thought to involve a loss of excitation energy when PSII becomes inactive and functions as a quencher rather than a photochemical trap (Öquist et al. 1992, Lee et al. 2001). There is conflicting evidence for (Eisenstadt et al. 2008) and against (Goss et al. 2006) qRC in diatoms. Both $q I$ and $q R C$ function independently of $\mathrm{qE}$ and $\mathrm{qT}$.

Relaxation of NPQ occurs as light is reduced or in darkness and the recovery time is a key characteristic often used to distinguish different quenching processes (Horton \& Hague 1988). In vascular plants and green algae, qE relaxes on time scales of seconds to minutes, qT relaxes on the order of $10 \mathrm{~min}$, qRC relaxes on time scales of minutes to an hour, and qI relaxes on the order of hours due to the requirement for protein synthesis to rebuild PSII reaction centers. In diatoms by contrast, qE relaxes on several time scales, from seconds to several 10 s of min and relaxation can require low light (Goss et al. 2006, Grouneva et al. 2007, 2008).

Since the emergence of fluorescence studies in oceanographic settings, it has been recognized that NPQ is an important variable affecting the fluorescence quantum yield (i.e. fluorescence emitted per unit light absorbed). Accordingly, NPQ impacts the relationship between chlorophyll concentration and fluorescence in the water column (Berman 1972) and total measured fluorescence between clear and cloudy days (Neville and Gower 1977). Furthermore, removing the effects of NPQ on fluorescence allows additional information to be retrieved on phytoplankton physiology and photosynthesis from the remaining variability in the corrected data (e.g. Falkowski \& Kiefer 1985, Morrison 2003, Westberry
\& Siegel 2003). Cullen \& Lewis (1995) have called for studies that focus on NPQ and fluorescence responses of phytoplankton grown in high light. However, few studies to date have measured fluorescence in cultures grown under high-light intensities delivered as diurnal or fluctuating light (Laney et al. 2005, Dimier et al. 2009, van de Poll et al. 2010). Understanding fluorescence variability under these conditions is important because they better represent the variable light conditions of natural systems. Proper representation of NPQ for the natural light environment is particularly important when evaluating satellite fluorescence data because these measurements register fluorescence properties of phytoplankton in the highly dynamic light environment of the surface mixed layer and are collected near noon and only under clear skies when incident irradiance is maximal (Behrenfeld et al. 2009).

Previous laboratory studies using constant light conditions have suggested that high-light-acclimated phytoplankton exhibit a strong NPQ response, while low-light-acclimated phytoplankton have reduced NPQ capacity (Niyogi et al. 1997, Cruz \& Serodio 2008, Ragni et al. 2008). Here we examine NPQ responses of Thalassiosira weissflogii grown under light conditions simulating natural surface layers of shallow and deep vertical mixing. Importantly, both conditions encompassed exposures to the same maximal light levels (i.e. the treatments simulated 2 mixing regimes with identical surface light levels). We find that lowlight-acclimated phytoplankton (i.e. deep mixing regime) exhibit higher NPQ than high-light-acclimated phytoplankton (i.e. shallow mixing). This finding thus directly contradicts previous conclusions regarding NPQ capacity and likely reflects the fact that earlier experiments have rarely employed growth conditions of fluctuating light with saturation of photochemistry well below the maximum light encountered by the cells. We also find that the fluorescenceversus-incident irradiance (iPAR) response curves do not saturate, suggesting the presence of a chl a fluorescence source that is insensitive to NPQ. This behavior of the fluorescence-iPAR relationship impacts the form of NPQ corrections applied to natural fluorescence data.

\section{MATERIALS AND METHODS}

\section{Culture conditions}

A culture of the marine diatom Thalassiosira weissflogii (clone Actin, CCMP 1336) was obtained 
from the Center for the Culture of Marine Protozoa. Cultures (1L) were grown under simulated shallow and deep mixing using natural seawater (from coastal Oregon) amended with f/2 nutrients. The medium was sterilized by autoclaving. Temperature was maintained at $20^{\circ} \mathrm{C}$. Light $\left(12 \mathrm{~h} \mathrm{~d}^{-1}\right)$ was provided by high intensity fluorescent tubes (55 W Dulux, Sylvania) with variable ballasts that were controlled by computer using Labview (ver. 6.0, National Instruments). Specifically, the diurnal light cycle (i.e. the light cycle representing daily changes in incident light at the surface ocean) ranged from $42 \mu \mathrm{mol}$ photons $\mathrm{m}^{-2} \mathrm{~s}^{-1}$ to a maximum of $1550 \mu \mathrm{mol}$ photons $\mathrm{m}^{-2} \mathrm{~s}^{-1}$ for both treatments (Fig. 1). Superimposed on this sinusoidal function were higherfrequency variations in light simulating shallow or deep vertical mixing with a realistic period of $1.5 \mathrm{~h}$ (D'Asaro 2003) (Fig. 1). In addition to these variable light conditions, we also examined the light dependent recovery of NPQ in cultures grown in continuous light of $500 \mu \mathrm{mol}$ photons $\mathrm{m}^{-2} \mathrm{~s}^{-1}$. Scalar irradiance in all culture vessels was continuously monitored with a $4 \pi$ sensor (Biospherical). Cultures were acclimated to each light condition for up to 6 mo and maintained at steady state growth for at least 2 wk prior to sampling. All sampling occurred early in the early exponential growth phase (cell abundance $<3 \times 10^{4} \mathrm{ml}^{-1}$ ).

\section{Physiological properties}

Coincident with NPQ measurements, we also collected samples for determination of chl a concentration, pigment spectral absorption, cell concentration, growth rate, and photosynthesis-irradiance relationships. Samples (20 to $30 \mathrm{ml}$ ) for chl a concentration were collected on glass fiber filters (GFF Whatman). Chlorophyll was extracted overnight with $90 \%$ acetone and determined spectrophotometrically following the methods of Jeffrey \& Humphrey (1975). Cell concentrations were measured using a Coulter (Multisizer 3) particle counter fitted with a $70 \mu \mathrm{m}$ aperture. Daily growth rates were calculated from sequential cell counts using the formula:

$$
\mu=\frac{\ln \left(C_{1} / C_{0}\right)}{t_{1}-t_{0}}
$$

where $\mu$ is the intrinsic rate of growth in units of $d^{-1}$, $C_{0}$ is initial $\left(t_{0}\right)$ cell concentration, and $C_{1}$ is the cell concentration $1 \mathrm{~d}$ later $\left(t_{1}\right)$.

Phytoplankton pigment absorption spectra were determined for each culture and light level using the glass fiber filter pad technique on a dual beam spectrophotometer (Shimadzu, UV2401 PC) and corrected for pathlength amplification following NASA protocols (Mitchell et al. 2003). The spectrally-averaged chl a-specific absorption cross-section $\left(\bar{a}^{*}\right)$ was calculated following Falkowski et al. (1985) for both the fluorescent tube and fluorometer blue light LED (see below) spectra:

$$
\bar{a}^{*}=\int_{400}^{750} a^{*}(\lambda) E(\lambda) d \lambda \cdot\left[\int_{400}^{750}[E(\lambda) d \lambda]\right]^{-1}
$$

where $E(\lambda)$ is the spectral irradiance of the light source and $a^{*}(\lambda)$ is the chl $a$-specific spectral absorption cross-section calculated from:

$$
a^{*}(\lambda)=2.3 \cdot A(\lambda) /(\mathrm{Chl})
$$

where $A(\lambda)$ is the sample spectral absorbance, 2.3 is the conversion factor from $\log 10$ to $\mathrm{ln}$, and $\mathrm{Chl}$ is the chl a concentration $\left(\mathrm{mg} \mathrm{m}^{-3}\right)$.

Photosynthesis-irradiance (PE) relationships for samples collected at noon were determined from 20 min incubations with ${ }^{14} \mathrm{C}$ bicarbonate following the photosynthetron protocol of Lewis \& Smith (1983). During each incubation, 10 irradiances were used, with the resultant data fit to the equation of Jassby \& Platt (1976):

$$
P^{\mathrm{B}}=P_{\text {max }}^{\mathrm{B}} \tanh \left(\alpha^{B} E / P_{\text {max }}^{\mathrm{B}}\right)
$$

where $P^{\mathrm{B}}$ is the photosynthetic rate normalized to chl $a, P_{\text {max }}^{\mathrm{B}}$ is the maximum chl a specific photosynthetic rate, $\alpha^{\mathrm{B}}$ is the chl a specific initial slope of the $\mathrm{PE}$ relationship, and $E$ is the photosynthetically active radiation (PAR: 400 to $700 \mathrm{~nm}$ ).

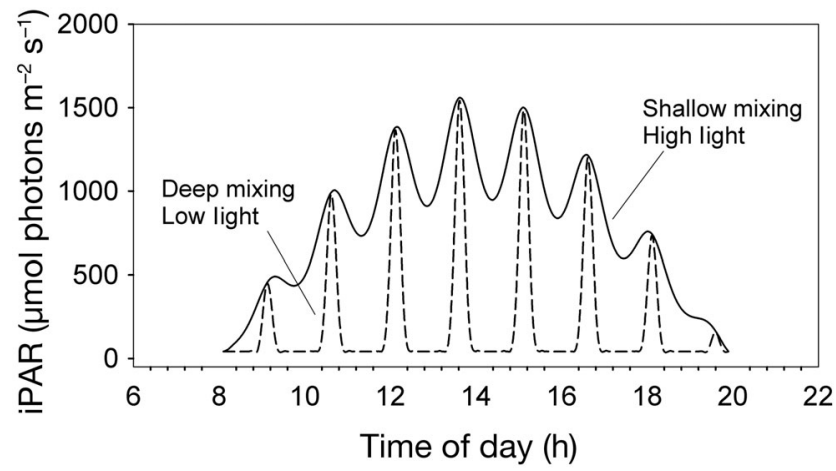

Fig. 1. Photoperiod (12 h) light regimes for simulated deep (dashed line) and shallow (solid line) mixing. Light was controlled by a variable-output ballast recreating both the sinusoidal function of daylight and a vertical mixing function with a period of $1.5 \mathrm{~h}$ (D'Asaro 2003). Maximum and minimum light $=1550$ and $42 \mu \mathrm{mol}$ photons $\mathrm{m}^{-2} \mathrm{~s}^{-1}$, respectively 


\section{Fluorescence and NPQ}

Fluorescence emission was determined in a temperature controlled $\left(20^{\circ} \mathrm{C}\right)$ pulse amplitude modulated (PAM) fluorometer (DUALPAM-100, Heinz Walz) fitted with a photomultiplier detector (DUALDPM). For fluorescence yield determinations, a sample was removed from the culture vessel, placed in the fluorometer, and dark acclimated for $25 \mathrm{~min}$. Initial fluorescence $\left(F_{0}\right)$ was then measured using a lowintensity blue LED source (DUAL-DB) running at a fixed frequency of $20 \mathrm{~Hz}$ and an intensity of $24 \mu \mathrm{mol}$ photons $\mathrm{m}^{-2} \mathrm{~s}^{-1}$. The sample was then exposed to a sequence of 20 blue actinic light levels ranging from 6 to $1952 \mu \mathrm{mol}$ photons $\mathrm{m}^{-2} \mathrm{~s}^{-1}$, with steady-state fluorescence $\left(F_{\mathrm{s}}\right)$ monitored continuously. At the end of each $7 \mathrm{~min}$ actinic light exposure, $F_{0}$ was remeasured during a brief exposure to darkness and then maximum fluorescence $\left(F_{\mathrm{m}}\right)$ determined with a saturating red LED flash of intensity of 3000 to $5000 \mu \mathrm{mol}$ photons $\mathrm{m}^{-2} \mathrm{~s}^{-1}$ and duration from 400 to $600 \mathrm{~ms}$. The specific intensity and duration of the saturating flash was determined prior to running the full fluorescence yield protocol to ensure saturation. From these measurements, variable fluorescence $\left(F_{\mathrm{v}} / F_{\mathrm{m}}\right)$ for each actinic light level was calculated as (Govindjee 2004):

$$
F_{\mathrm{v}} / F_{\mathrm{m}}=\left(F_{\mathrm{m}}-F_{\mathrm{o}}\right) / F_{\mathrm{m}}
$$

where $F_{\mathrm{m}}$ and $F_{\mathrm{o}}$ are determined at the end of actinic light exposure. Fluorescence yields $\left(F_{\mathrm{Y}}\right)$ were then calculated for each light level as (Govindjee 2004):

$$
F_{\mathrm{Y}}=\left(F_{\mathrm{S}} / F_{\mathrm{o}}\right)-1
$$

where $F_{\mathrm{o}}$ is the $F_{\mathrm{o}}$ value measured when $F_{\mathrm{v}} / F_{\mathrm{m}}$ was maximal (i.e. when NPQ was fully relaxed; see 'Results') and functions to account for differences in total pigment absorption between samples.

NPQ kinetics were determined using a PAM protocol entailing an initial dark acclimation period of $25 \mathrm{~min}$, followed by an actinic light exposure of $10 \mathrm{~min}$, and finally a second dark period of $35 \mathrm{~min}$. During the first dark period, $F_{\mathrm{o}}$ was monitored continuously using the low-intensity blue LED described above and $F_{\mathrm{m}}$ measured periodically (to determine $F_{\mathrm{v}} / F_{\mathrm{m}}$ ) with a saturating red LED flash (as above). During the subsequent actinic light exposure, the sample was exposed to a single background saturating light level of $1100 \mu \mathrm{mol}$ photons $\mathrm{m}^{-2} \mathrm{~s}^{-1}$ to induce NPQ. Throughout this period, $F_{\mathrm{S}}$ was continuously monitored and maximum fluorescence under actinic light exposure $\left(F_{\mathrm{m}}{ }^{\prime}\right)$ periodically determined. NPQ was calculated as (Govindjee 2004):

$$
\mathrm{NPQ}=\left(F_{\mathrm{m}} / F_{\mathrm{m}}{ }^{\prime}\right)-1
$$

During the final dark period, $F_{\mathrm{o}}$ was continuously monitored and the kinetics of fluorescence recovery and NPQ relaxation determined through frequent determinations of $F_{\mathrm{m}}$.

One of the motivations for these experiments was to characterize phytoplankton fluorescence properties relevant to the interpretation of satellite fluorescence data. Accordingly, samples for fluorescence yield and NPQ kinetics measurements were collected at midday. This sampling strategy ensured that all data were consistent with respect to their position within the photoperiod; however, they differed with respect to the incident light level at the time of sampling (see 'Results' section),

To further examine details of NPQ relaxation, samples from the continuous light cultures $(500 \mu \mathrm{mol}$ photons $\mathrm{m}^{-2} \mathrm{~s}^{-1}$ ) were collected and fluorescence measured during a modified protocol of $3 \mathrm{~h}$ darkness, 15 min actinic light $\left(140 \mu \mathrm{mol}\right.$ photons $\left.\mathrm{m}^{-2} \mathrm{~s}^{-1}\right)$, and then 20 min darkness. Throughout this protocol, $F_{\mathrm{o}}$ was monitored continuously and $F_{\mathrm{m}}$ and $F_{\mathrm{m}}$ ' measured periodically (as above). Five replicate experiments were conducted.

Finally, we evaluated variability in the magnitude of NPQ over the diurnal cycle in the 2 simulated mixing conditions by conducting fluorescence measurements on samples collected at $2 \mathrm{~h}$ intervals over the daytime cycle ( 5 samples $\mathrm{d}^{-1}$ for $3 \mathrm{~d}$ ). Samples were dark acclimated for $30 \mathrm{~min}$ and exposed to 10 actinic light levels for $5 \mathrm{~min}$, with intervening 5 min dark periods. During the dark phase of this protocol, we monitored $F_{\mathrm{o}}$ continuously and measured $F_{\mathrm{m}}$ (to determine $F_{\mathrm{v}} / F_{\mathrm{m}}$ ) just prior to the actinic light exposure. $F_{\mathrm{m}}{ }^{\prime}$ was measured at the end of each actinic light period to determine NPQ.

\section{RESULTS}

\section{Photoacclimation state}

Thalassiosira weissflogii grew at equivalent rates $\left(0.95\right.$ to $\left.0.96 \mathrm{~d}^{-1}\right)$ in the 2 light conditions simulating shallow and deep mixing. This result implies that cells in the deep-mixing regime adjusted their light harvesting capacity to fully compensate for their lower daily light exposure. This acclimation was observed as a 3-fold increase in cellular chl a concentration in the low-light (deep mixing) treatment (Table 1), which consequently decreased the chl a normalized absorption cross section $\left(\bar{a}^{*}\right)$ in a manner 
Table 1. Thalassiosira weissflogii. Growth and photosynthetic parameters for cultures grown under simulated shallow- and deep-mixing light regimes. Absorption cross sections are calculated using spectral distribution for fluorescent lights $\left(\bar{a}^{*}\right.$ Fluor $)$ under growth conditions and blue light emitting diodes $\left(\bar{a}^{*}\right.$ LED $)$ used as light source in Dual-PAM. Values in parentheses $=$ SD for triplicates

\begin{tabular}{|c|c|c|c|c|c|c|}
\hline \multirow{2}{*}{$\begin{array}{l}\text { Mixing } \\
\text { regime light } \\
\text { treatment }\end{array}$} & \multirow{2}{*}{$\begin{array}{c}\text { Mean light } \\
\text { intensity }(\mu \mathrm{mol} \\
\left.\text { quanta } \mathrm{m}^{-2} \mathrm{~s}^{-1}\right)\end{array}$} & \multirow{2}{*}{$\begin{array}{c}\text { Integrated } \\
\text { flux }(\mathrm{mol} \\
\left.\text { quanta } \mathrm{m}^{-2} \mathrm{~d}^{-1}\right)\end{array}$} & \multirow{2}{*}{$\begin{array}{c}\text { Specific } \\
\text { growth rate } \\
\left(\mathrm{d}^{-1}\right)\end{array}$} & \multirow{2}{*}{$\begin{array}{l}\text { Chl a quota } \\
(\mathrm{pg} \mathrm{chl} \mathrm{a} \\
\left.\text { cell }^{-1}\right)\end{array}$} & \multicolumn{2}{|c|}{$\begin{array}{l}\text { Spectrally weighted, chl a normalized } \\
\text { absorption cross section }\left(\mathrm{m}^{2} \mathrm{mg} \mathrm{chl} a^{-1}\right)\end{array}$} \\
\hline & & & & & $\bar{a}_{\text {Fluor }}^{*}$ & $\bar{a}_{\text {LED }}^{*}$ \\
\hline $\begin{array}{l}\text { Shallow mixin } \\
\text { High light }\end{array}$ & 487 & 20.8 & $0.96(0.26)$ & $1.51(0.19)$ & $2.44 \times 10^{-3}(0.91)$ & $9.8 \times 10^{-3}(0.19)$ \\
\hline $\begin{array}{l}\text { Deep mixing } \\
\text { Low light }\end{array}$ & 138 & 5.9 & $0.95(0.08)$ & $4.68(0.10)$ & $2.02 \times 10^{-3}(0.37)$ & $6.92 \times 10^{-3}(0.14)$ \\
\hline
\end{tabular}

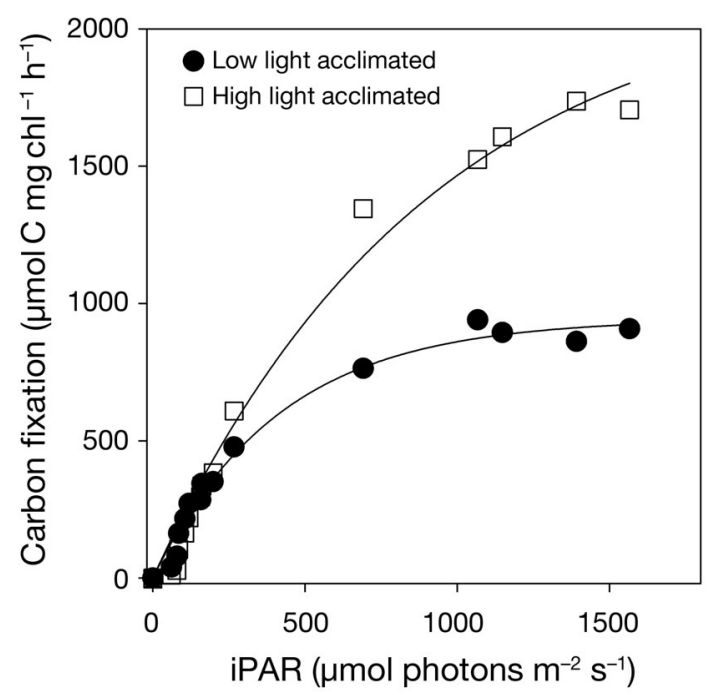

Fig. 2. Thalassiosira weissflogii. Photosynthesis vs. irradiance (PE) response curves for low- and high-lightacclimated cultures. Data are fit to Eq. (4) (Jassby \& Platt 1976). Low light: $\alpha^{\mathrm{B}}=2.29$ ( $\mu \mathrm{mol} \mathrm{C} \mathrm{mg} \mathrm{chl} \mathrm{a} \mathrm{h}^{-1}$ [ $\mu \mathrm{mol}$ photons $\left.\mathrm{m}^{-2} \mathrm{~s}^{-1} \mathrm{~J}^{-1}\right)$, photosynthetic rate $P_{\max }=943(\mu \mathrm{mol} \mathrm{C} \mathrm{mg}$ chl $\mathrm{a} \mathrm{h}^{-1}$ ), saturation irradiance $E_{\mathrm{k}}=411\left(\mu \mathrm{mol}\right.$ photons $\mathrm{m}^{-2}$ $\left.\mathrm{s}^{-1}\right)$. High light: $\alpha^{\mathrm{B}}=2.43\left(\mu \mathrm{mol} \mathrm{C} \mathrm{mg} \mathrm{chl} \mathrm{a} \mathrm{h}^{-1}\right.$ [ $\mu \mathrm{mol}$ photons $\left.\mathrm{m}^{-2} \mathrm{~s}^{-1} \mathrm{~J}^{-1}\right), P_{\text {max }}^{\mathrm{B}}=2185\left(\mu \mathrm{mol} \mathrm{C} \mathrm{mg} \mathrm{chl} \mathrm{a} \mathrm{h}{ }^{-1}\right), E_{\mathrm{k}}=899(\mu \mathrm{mol}$ photons $\mathrm{m}^{-2} \mathrm{~s}^{-1}$ ). If we assume that $P^{\mathrm{B}}$ max cannot exceed measured values, and hold $P^{\mathrm{B}}{ }_{\text {max }}$ at 1720 and $910 \mu \mathrm{mol}$ photons $\mathrm{m}^{-2} \mathrm{~s}^{-1}$ for high- and low-light respectively, $E_{\mathrm{k}}$ becomes 707 and $398 \mu \mathrm{mol}$ photons $\mathrm{m}^{-2} \mathrm{~s}^{-1}$, respectively

consistent with increased self-shading (Falkowski et al. 1985). Photosynthesis versus irradiance curves yielded similar initial slopes $\left(\alpha^{\mathrm{B}}\right)$ for the 2 mixing regimes, but maximum rates $\left(P_{\max }^{\mathrm{B}}\right)$ that were nearly 2 -fold greater in the high-light-acclimated (shallow mixing) cells (Fig. 2). As growth rates were equivalent between the 2 treatments (i.e. similar carbon fixing capacity), this difference in $P^{\mathrm{B}}{ }_{\text {max }}$ is driven in part by the normalization of $P_{\max }$ to the lower cellular chl $a$ in high light (Table 1).

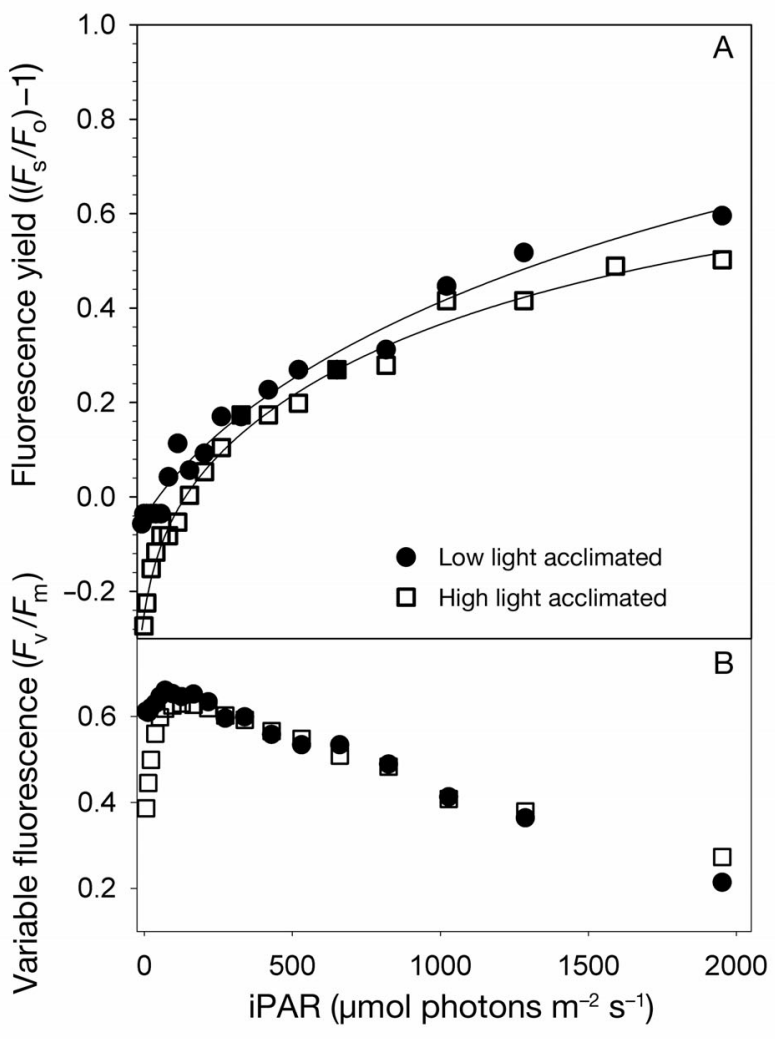

Fig. 3. Thalassiosira weissflogii. (A) Fluorescence yields in low- and high-light-acclimated cultures. Note: $F_{\mathrm{o}}$ used in the calculation of $F_{\mathrm{Y}}$ is determined at maximum $F_{\mathrm{v}} / F_{\mathrm{m}}$. (B) Dark measured variable fluorescence $\left(F_{\mathrm{v}} / F_{\mathrm{m}}\right)$ for same treatments as (A)

\section{Fluorescence yield}

Noon-time PAM-derived fluorescence yields $\left(F_{\mathrm{Y}}\right)$ were similar in both light treatments (Fig. 3A). This finding was not expected because total light absorption differs between high- and low-light-acclimated cultures (Table 1). Specifically, taking the product of 
cellular chl $a$ and $\bar{a}^{*}$ for the blue light LED spectrum (Table 1), we obtained cellular absorption cross section values of $14.8 \times 10^{-12}$ and $32.4 \times 10^{-12} \mathrm{~m}^{2} \mathrm{cell}^{-1}$ for the high-light and low-light treatments respectively. This 2.2 fold higher light absorption in low-light cells (1) is driven primarily through changes in pigment concentration, (2) should result in higher fluorescence yields for low-light-acclimated cultures, and (3) suggests that there are significant differences in NPQ capacity in these treatments.

As noted in the 'Materials and methods' section above, the calculation of $F_{\mathrm{Y}}$ requires assessment of $F_{\mathrm{o}}$ when NPQ is fully relaxed. In Thalassiosira weissflogii, NPQ had a greater impact on $F_{\mathrm{m}}$ than $F_{\mathrm{o}}$. Thus, observed changes in $F_{\mathrm{v}} / F_{\mathrm{m}}$ (Eq. 5) can be used to evaluate the NPQ relaxation state. During our fluorescence yield experiments, we observed that $F_{\mathrm{v}} / F_{\mathrm{m}}$ rose to a maximum (0.63 to 0.66) at 70 and $126 \mu \mathrm{mol}$ photons $\mathrm{m}^{-2} \mathrm{~s}^{-1}$ for low and high light, respectively, and then declined at higher light levels (Fig. 3B). Although our $F_{\mathrm{Y}}$ results are calculated using $\mathrm{F}_{\mathrm{o}}$ values at maximum $F_{\mathrm{v}} / F_{\mathrm{m}}$, this initial rise in $F_{\mathrm{v}} / F_{\mathrm{m}}$ indicates that NPQ was still relaxing at these lowest light levels. In other words, the assumption of negligible NPQ after 25 min of dark acclimation prior to the actinic light sequence is violated.

\section{NPQ dynamics}

Fluorescence properties for low-light and highlight cultures for our NPQ induction-relaxation protocol are shown in Fig. 4A \& B, respectively. At the time of sampling (noon), the high-light cultures were receiving near maximum iPAR $(1100 \mu \mathrm{mol}$ photons $\mathrm{m}^{-2} \mathrm{~s}^{-1}$ ) while the low-light cultures were receiving only $42 \mu \mathrm{mol}$ photons $\mathrm{m}^{-2} \mathrm{~s}^{-1}$. Given this difference, we would anticipate that the low-light cells would be expressing little NPQ at the time of sampling, while the high-light cells would express high NPQ. Comparison of fluorescence emissions between treatments during the initial 25 min dark period shows that the low-light-acclimated cells had much higher variable fluorescence $\left(F_{\mathrm{v}} / F_{\mathrm{m}}\right)$ than the high-light cells (Fig. 4). This finding is consistent with anticipated differences in NPQ, as variable fluorescence values can be high only when NPQ is minimal. Furthermore, the persistently low $F_{\mathrm{v}} / F_{\mathrm{m}}$ values for the highlight cells indicates that NPQ relaxed little during the initial dark period of the PAM protocol.

A common assumption applied in PAM measurements of NPQ is that pre-exposure of phytoplankton samples to a period of darkness before the NPQ-

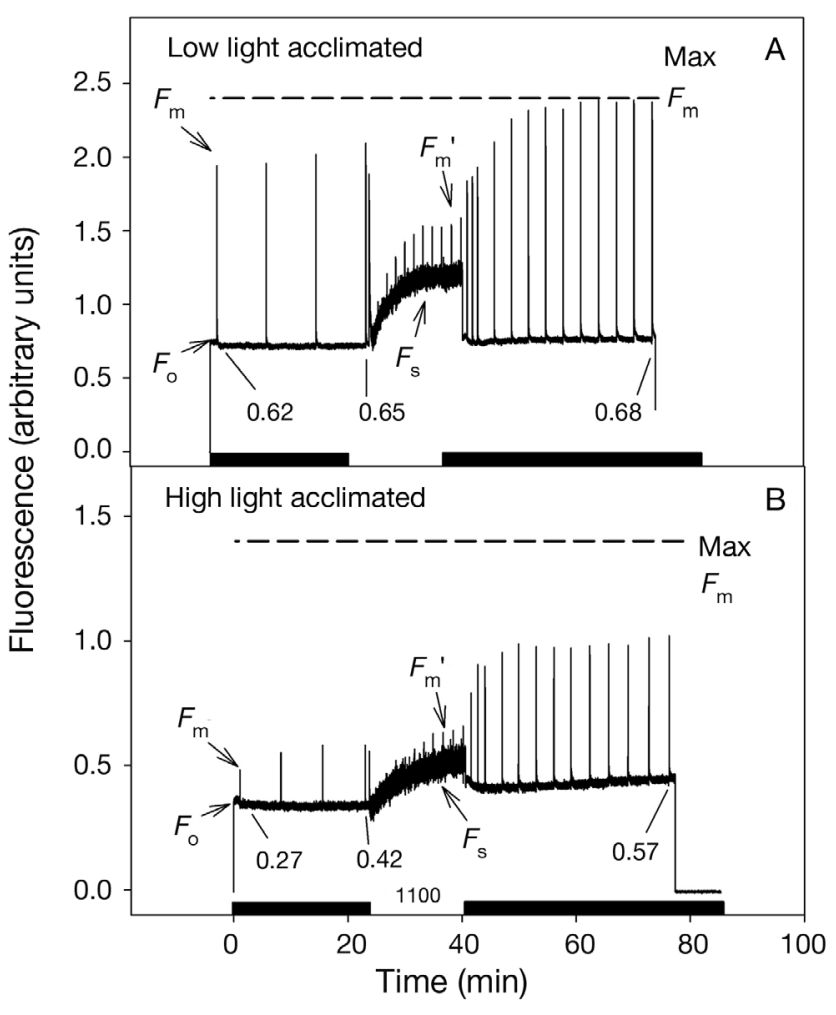

Fig. 4. Thalassiosira weissflogii. Example fluorescence traces of (A) low- and (B) high-light-acclimated cultures sampled at noon $(14: 10 \mathrm{~h})$. Light intensities at the time of sampling were 42 and $1100 \mu \mathrm{mol}$ photons $\mathrm{m}^{-2} \mathrm{~s}^{-1}$ for lowand high-light-acclimated cultures, respectively. Samples were first exposed to a dark period of 25 min (black bar on $x$ axes), during which initial $\left(F_{\mathrm{o}}\right)$ and maximum $\left(F_{\mathrm{m}}\right)$ fluorescence were monitored. Fluorescence $\left(F_{\mathrm{s}}\right)$ and maximum fluorescence $\left(F_{\mathrm{m}}{ }^{\prime}\right)$ were then monitored during a $15 \mathrm{~min}$ exposure to super-saturating background light $(1100 \mu \mathrm{mol}$ photons $\mathrm{m}^{-2} \mathrm{~s}^{-1}$ ). Finally, fluorescence recovery was observed over a subsequent 20 min dark period (black bar on $x$-axes). Variable fluorescence $\left(F_{\mathrm{v}} / F_{\mathrm{m}}\right)$ values are given for 3 points in each time course (at the beginning of each protocol, after exposure to saturating light, and at the end of the second dark period). Maximum $F_{\mathrm{v}} / F_{\mathrm{m}}$ for $T$. weissflogii under our growth conditions (when NPQ is fully relaxed) = 0.6 to 0.65 (horizontal dashed line)

induction protocol (i.e. exposure to high actinic light) is adequate for full relaxation of pre-existing NPQ. Results in Fig. 4B show that this assumption was not valid for Thalassiosira weissflogii under our conditions. This retention of NPQ through the initial dark period is clear from the difference between the $F_{\mathrm{m}}$ values and observed $F_{\mathrm{m}}$ associated with maximal $F_{\mathrm{v}} / F_{\mathrm{m}}$ (horizontal dashed lines in Fig. 4).

In both treatments, the rise in $F_{\mathrm{m}}$ during the initial dark period is small. However, during the dark period following actinic light exposure, a more dramatic rise in $F_{\mathrm{m}}$ is observed (Fig. 4), suggesting that 


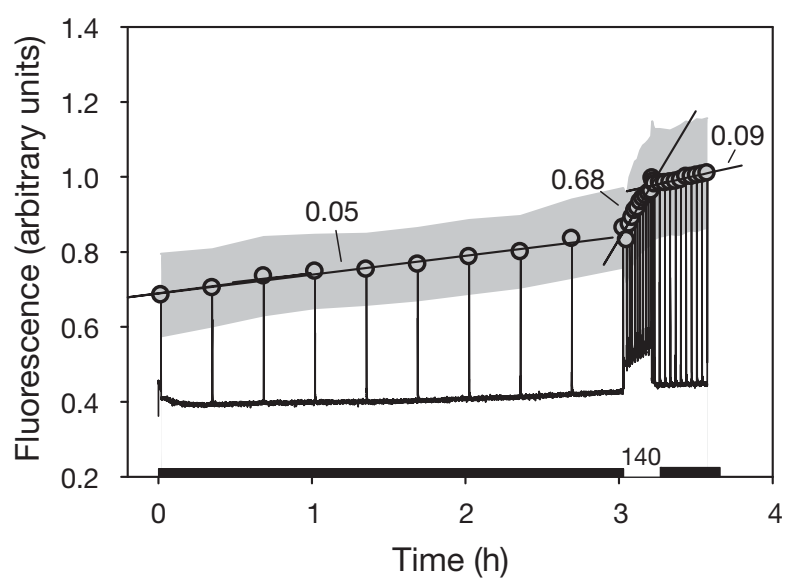

Fig. 5. Thalassiosira weissflogii. Expanded time-course of dark relaxation of non-photochemical quenching (NPQ) in cultures grown under continuous light of $500 \mu \mathrm{mol}$ photons $\mathrm{m}^{-2} \mathrm{~s}^{-1}$. Maximum fluorescence rises only gradually for the first $3 \mathrm{~h}$ of darkness (black bar on $\mathrm{x}$-axis), but then quickly rises with a background illumination of $140 \mu \mathrm{mol}$ photons $\mathrm{m}^{-2} \mathrm{~s}^{-1}$. Values: slopes of each regression line. Each point is average of 5 replicates. Shaded area: $95 \%$ CI

NPQ relaxation in Thalassiosira weissflogii was enhanced by previous light exposure. This recovery is greatest during the first 6 to $8 \mathrm{~min}$ following actinic light for both treatments, a time scale consistent with qE relaxation (Holt et al. 2004). It is important to note that the incomplete NPQ relaxation in the initial dark period has consequences for derived fluorescence properties. Of particular interest, it can result in underestimates, or even negative values, of calculated NPQ (i.e. $F_{\mathrm{m}}<F_{\mathrm{m}}{ }^{\prime}$; Eq. 7 ).

We further examined the light dependency of NPQ relaxation using samples from our constant light condition. Despite a prolonged $3 \mathrm{~h}$ initial dark period, maximum fluorescence exhibited little recovery (increasing from $\sim 0.7$ to 0.8 ) (Fig. 5). However, a marked increase in NPQ recovery was observed upon exposure to low-level actinic irradiance. Recovery, slowed again during subsequent exposure to darkness (Fig. 5). This result demonstrates that complete relaxation of NPQ in Thalassiosira weissflogii requires light energy when cells are harvested from growth conditions that induce NPQ.

\section{NPQ capacity}

Fluorescence properties illustrated in Figs. $3 \& 4$ are all for samples collected at midday. We additionally investigated NPQ capacities over the diurnal light cycle. As described in the 'Materials and methods' section, these assessments entailed sequential light-dark exposures that generally ensured NPQ relaxation and high $F_{\mathrm{v}} / F_{\mathrm{m}}$ within 40 to 50 min into the protocol. NPQ capacities were calculated using $F_{\mathrm{m}}{ }^{\prime}$ values observed at each actinic light level and the $F_{\mathrm{m}}$ value associated with the maximum $F_{\mathrm{v}} / F_{\mathrm{m}}$ value exceeding 0.6 (Eq. 7). We found NPQ capacity to be independent of diurnal sampling time (thus recent light history) for the low light cultures. The relationship between NPQ and iPAR for the pooled data is shown by the black symbols in Fig. 6. For the high light treatment, full NPQ relaxation $\left(F_{\mathrm{v}} / F_{\mathrm{m}}>0.6\right)$ was achieved on 3 occasions. Pooling these data yields the NPQ-iPAR relationship shown by open symbols in Fig. 6. The 2 growth conditions both give relationships that begin with declining NPQ at low-light levels because of incomplete relaxation early in the protocol, as discussed above. NPQ values then begin to rise above 70 and $240 \mu \mathrm{mol} \mathrm{m}^{-2} \mathrm{~s}^{-1}$ for low- and highlight Thalassiosira weissflogii, respectively (Fig. 6). The 2.3-fold higher NPQ for the low-light-acclimated cells is consistent with the 2.2-fold higher cellular absorption cross section calculated for low-lightacclimated cells. This finding suggests that the lack of difference in $F_{\mathrm{Y}}$ relationships between treatments (Fig. 3A) was due to enhanced NPQ in the low-light treatment.

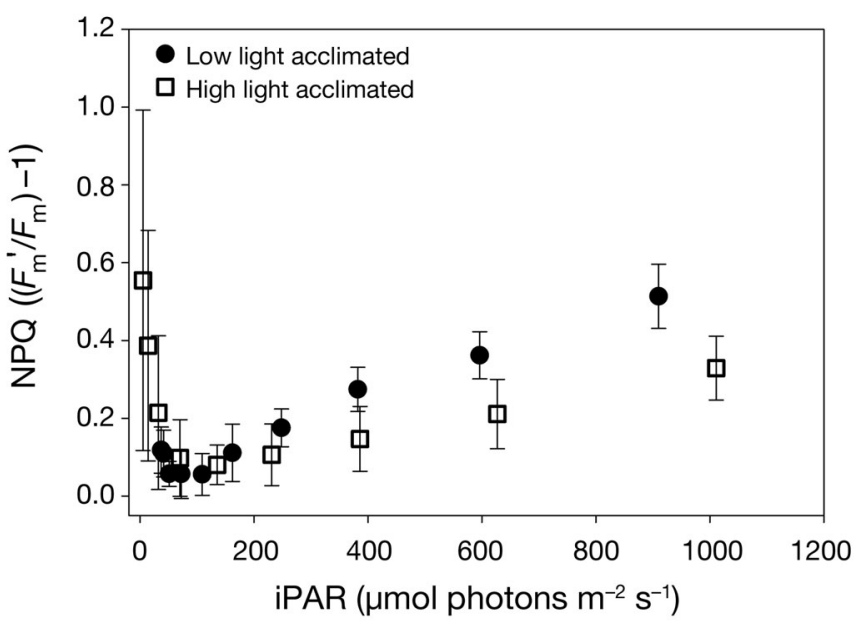

Fig. 6. Thalassiosira weissflogii. Comparison of non-photochemical quenching (NPQ) in low- and high-lightacclimated cultures plotted against incident irradiance (iPAR). Low-light represents 5 light curves (1 every $2 \mathrm{~h}$ ) collected over a period of $3 \mathrm{~d}$ (each point is average of 15 values) under semicontinuous culture conditions. For highlight data only 3 light curves (3 out of 15 data sets) met the criteria of $F_{\mathrm{v}} / F_{\mathrm{m}}>0.6$. Error bars $=\mathrm{SD}$ 


\section{DISCUSSION}

Field and satellite measurements of fluorescence are a potentially powerful tool for optically quantifying chl a concentrations and investigating variability in phytoplankton physiology. These applications, however, require a thorough understanding of the fluorescence-iPAR relationship because of the strong influence of NPQ on the quantum yield of fluorescence. This problem is particularly acute when interpreting satellite-based retrievals of fluorescence, as these data are acquired under clear-sky, near-noon conditions when incident light is maximal. We examined fluorescence-iPAR relationships with a culture system that simulated the vertically-mixing, upper water column to test whether low-light-acclimated phytoplankton (i.e. deep mixing) have greater NPQ than those that are high-light-acclimated (i.e. shallow mixing). This approach differs from many previous NPQ investigations that have employed the unnatural conditions of constant low and/or high light. Importantly, both light environments used in the current study saturated growth of Thalassiosira weissflogii, but the different simulated mixing regimes yielded 2 distinctly different photoacclimations states, as evidenced by changes in chl a cell quotas and PE relationships.

\section{Fluorescence response to light acclimation}

Close inspection of data in Fig. 2 shows a separation in PE curves between the 2 simulated mixing conditions beginning around $180 \mu \mathrm{mol}$ photons $\mathrm{m}^{-2}$ $\mathrm{s}^{-1}$, well below the light level for saturation of carbon fixation $\left(E_{\mathrm{k}-\mathrm{C}}\right)$. Measurements of $F_{\mathrm{v}} / F_{\mathrm{m}}$ for these treatments likewise revealed a progressive decrease above $\sim 150 \mu \mathrm{mol}$ photons $\mathrm{m}^{-2} \mathrm{~s}^{-1}$, indicating increasing NPQ (Fig. 3B). This early induction of NPQ below the $E_{\mathrm{k}-\mathrm{C}}$ has also been reported by Laney et al. (2005) and Ting \& Owens (1993). These findings have 2 important implications. First, the saturation irradiance for fluorescence $\left(E_{\mathrm{k}-\mathrm{F}}\right)$ is not a quantitative measure of $E_{\mathrm{k}-\mathrm{C}}$ (Laney et al. 2005). Second, modeling of NPQ for corrections to satellite fluorescence data (e.g. Behrenfeld et al. 2009) should describe NPQ induction as a function of $E_{\mathrm{k}-\mathrm{F}}$, rather than $E_{\mathrm{k}-\mathrm{C}}$.

\section{NPQ dynamics}

Results from our $F_{\mathrm{Y}}$ experiments also demonstrate an increase in $F_{\mathrm{v}} / F_{\mathrm{m}}$ at the very lowest light levels
(Fig. 3B). This result would not be expected if NPQ was fully relaxed prior to the actinic light exposures (Ting \& Owens 1994). Thus our initial 25 min dark period was not sufficient for complete relaxation. This finding is noteworthy because dark acclimation times of 5 to $30 \mathrm{~min}$ are often used to relax NPQ in diatom studies (Lavaud et al. 2007, Miloslavina et al. 2009). Our additional experiments with cells acclimated to constant light show that low-light pretreatment is required to completely relax NPQ (Fig. 5), in agreement with several recent diatom-specific NPQ studies (Ting \& Owens 1993, Grouneva et al. 2008, 2009, Miloslavina et al. 2009). The failure of $F_{\mathrm{m}}$ values to rise to maximal levels during dark pretreatment (Fig. 4) is thought to be due to a light requirement for $\mathrm{qE}$ relaxation in diatoms. More specifically, NADPH is required to convert the quenching xanthophyll, diatoxanthin, to its epoxidated non-quenching state, diadinoxanthin (Grouneva et al. 2009). This reductant is supplied through photosynthesis, creating a direct link between NPQ relaxation and availability of light energy (Jakob et al. 2001, Grouneva et al. 2009). There is also evidence that diatoms induce NPQ in darkness through chlororespiratory reduction of the plastiquinone pool and establishment of a weak transthylakoid pH gradient (Ting \& Owens 1993, Jakob et al. 2001, Dijkman \& Kroon 2002). This electron flow is much slower than PSI turnover, such that exposure to low light reoxidizes the plastiquinone pool and relaxes NPQ (Grouneva et al. 2009).

\section{NPQ capacity}

One issue of particular interest during this study was the relationship between NPQ and growth irradiance conditions. Behrenfeld et al. (2009) proposed that the fluorescence quantum yield at a given iPAR value will be dependent on the photoacclimation state of the phytoplankton population. They envisioned low-light-acclimated cells (i.e. low $E_{\mathrm{k}-\mathrm{F}}$ ) as showing earlier induction of NPQ and thus lower fluorescence emission at a given iPAR than high-lightacclimated cells (Fig. 7). Our findings demonstrate a greater capacity and earlier induction of NPQ in lowlight-acclimated cells than high-light, in agreement with the predictions of Behrenfeld et al. (2009). Greater NPQ capacity in low-light-acclimated cells may at first appear to contradict results from previous algal NPQ studies, where NPQ capacity was greatest in high-light treatments (Niyogi et al. 1997, Cruz \& Serodio 2008, Ragni et al. 2008). However, these 


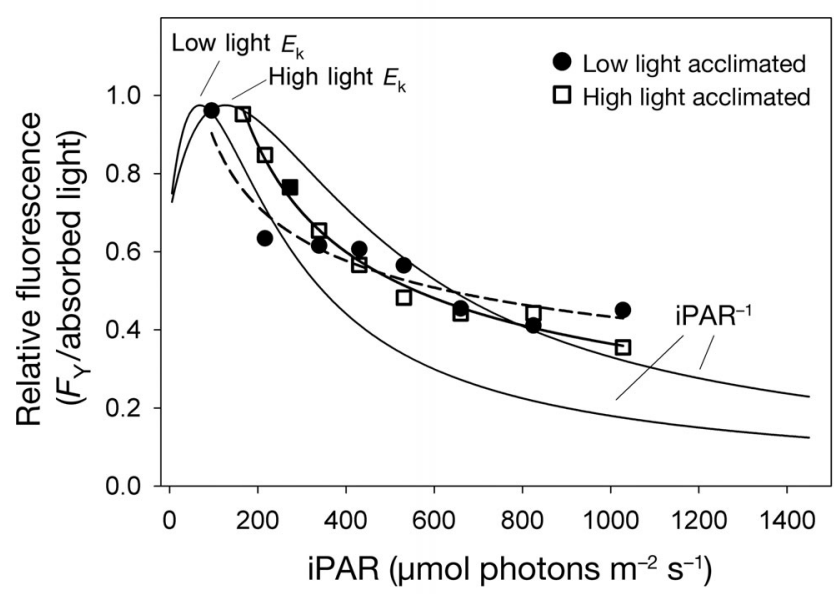

Fig. 7. Thalassiosira weissflogii. Fluorescence response of low- and high-light-acclimated cultures normalized to iPAR and hypothesized curves of quantum yield for 2 different photoacclimation states (Behrenfeld et al. 2009). With increasing iPAR, there is a rise in fluorescence as reaction centers close. At $E_{\mathrm{k}-\mathrm{F}}$ light reactions are saturated and fluorescence declines as an inverse function of incident light $\left(\mathrm{PAR}^{-1}\right)$ as each additional photon is lost as heat through NPQ. Data points are from light levels $>E_{\mathrm{k}-\mathrm{F}}$. Data $<E_{\mathrm{k}-\mathrm{F}}$ do not follow a power function. Low-light fit (dashed line): $Y=0.037 \times \mathrm{iPAR}^{-0.31} ;$ High-light fit: $Y=0.155 \times \mathrm{iPAR}^{-0.54}$. $95 \%$ CI for exponents $=0.1$ and 0.04 for low- and highlight, respectively

earlier studies used constant high- and low-light conditions and were focused on resolving NPQ mechanisms, rather than characterizing the fluorescence-iPAR relationship. Of the few studies that have employed fluctuating light, the focus has generally been on examining short-term responses to increased light flux (Lavaud et al. 2007, van de Poll et al. 2007, 2010), rather than steady-state fluorescence characteristics of fully acclimated cultures (Dimier et al. 2009). We therefore propose that the apparent discrepancies between our results and earlier findings largely reflect differences in the culturing conditions employed. Specifically, phytoplankton maintained at a constant low-light level have little need to protect PSII from photodamage. In contrast, growth under constant high-light requires a much larger NPQ capacity to safely dissipate the excess absorbed light energy. In a variable light regime ranging from subto super-saturating intensities (as experienced by a vertically mixed population), phytoplankton must simultaneously have attributes of both high- and low-light acclimated cells. In particular and as observed here for Thalassiosira weissflogii, such conditions require both enhanced light absorption capacity (i.e. increased cellular pigment levels) for periods of low-light exposure near the bottom of the mixing layer and high NPQ capacity to dissipate the great excess of absorbed light energy experienced near noon at the surface of the mixing layer.

We find that the magnitude of NPQ (maximum of 0.5) in Thalassiosira weissflogii is lower than previous studies but within the general range for diatoms (0.5 to 2.5) (Lavaud et al. 2007). Variability in NPQ magnitude within a species can be large and is related to growth conditions. For instance, NPQ in Phaeodactylum tricornutum ranges from a value of 2.3 for cultures grown under a 1:1 h light:dark cycle at $45 \mu \mathrm{mol}$ photons $\mathrm{m}^{-2} \mathrm{~s}^{-1}$ (Lavaud et al. 2007) to a value of 6.0 for cultures grown under a 5:55 $\mathrm{min}$ light:dark cycle at $40 \mu \mathrm{mol}$ photons $\mathrm{m}^{-2} \mathrm{~s}^{-1}$ (Ruban et al. 2004). These growth conditions are, of course, far from natural and highlight the fact that many NPQ studies focus on resolving NPQ mechanisms rather than NPQ behavior in natural settings.

\section{Application to fluorescence studies}

Our results show that the $F_{\mathrm{Y}}$-iPAR relationship does not saturate in Thalassiosira weissflogii (Fig. 3). This finding agrees with the laboratory and field observations of Laney et al. (2005) and Morrison (2003), but contrasts with field observations of Schallenberg et al. (2008). In this latter study, saturation of in situ fluorescence was observed in all profiles but one. However, it appears that non-saturating fluorescence is the more common behavior and it implies that there is an NPQ-insensitive source of fluorescence that increases with iPAR. One likely candidate for this residual fluorescence is PSI. PSI has no variable fluorescence and exciton trapping is more efficient than in PSII, but it still gives a low, constant background fluorescence signal (but see Joly \& Carpentier 2007). To evaluate the PSI contribution necessary to explain our nonsaturating $F_{\mathrm{Y}}$-iPAR relationships (Fig. 3), we employed the fluorescence model of Behrenfeld et al. (2009). We find that PSI contributions of 8.5 and $11.9 \%$ give best fits to our data for high- and low-light cultures, respectively. These values are in close agreement with reports that PSI fluorescence is $\sim 10 \%$ of total cellular fluorescence (Franck et al. 2002). Furthermore, the slightly higher PSI contribution for the low-light condition is consistent with earlier findings suggesting that lowlight acclimation can cause a decrease in PSII:PSI (Strzepek \& Harrison 2004).

It is important to note that the contribution of PSI to cellular fluorescence is wavelength dependent and 
therefore dependant on the type of instrument and filter sets used. Peak fluorescence emission of PSI in vivo is $\sim 722 \mathrm{~nm}$ and is minimal around the in vivo fluorescence peak of PSII (684 nm) (Franck et al. 2002, 2003). The fluorometer used in this study is equipped with a $665 \mathrm{~nm}$ cut-off filter, so all PSI fluorescence (>665 nm) is included in the fluorescence measurement. For fluorescence studies in marine systems, radiometers are often employed with narrow band (683 with $10 \mathrm{~nm}$ half-maximum band-width) fluorescence detection (Morrison 2003, Schallenberg et al. 2008). The Moderate-resolution Imaging Spectroradiometer (MODIS) ocean color sensor uses a similar narrow band method although it is centered at $678 \mathrm{~nm}$ to avoid an atmospheric oxygen absorption band (Behrenfeld et al. 2009). Using narrow bandpass detection will minimize the fluorescence signal from PSI, but even at $685 \mathrm{~nm}$ the PSI contribution can be as high as $10 \%$ at low iPAR (Franck et al. 2002). The contribution of PSI to total fluorescence under brief high iPAR exposure is very low $(\sim 0.2 \%)$, but under sustained high iPAR it increases due to NPQ of PSII fluorescence (Franck et al. 2002, Govindjee 2004). Given that field-measured quantum yields of fluorescence decline roughly 5-fold with NPQ, we might expect the contribution of PSI fluorescence to be an important contributor to total fluorescence (Morrison 2003). A better understanding of the contribution of PSI to fluorescence in phytoplankton is clearly needed.

Satellite-derived natural fluorescence is by necessity measured in the presence of high photon flux and, as such, is influenced by the multiple NPQ pathways. In order to use these data as a physiological indicator, it is necessary to first correct for the confounding NPQ signal. Behrenfeld et al. (2009) applied an inverse incident light function (1/iPAR) to MODIS fluorescence data as a first-order NPQ correction, but recognized that this function assumed NPQ behaved as a perfect protective quencher. They also noted that the NPQ correction should also account for photoacclimation and that neglecting this component likely impacted derived fluorescence quantum yields at high latitudes and under deep mixing conditions. Findings of the current study provide insight on the concerns raised by Behrenfeld et al. (2009) regarding the inverse-light function applied for NPQ correction. Our results demonstrate enhanced NPQ capacity in low-lightacclimated cells and illustrate the non-saturable nature of $F_{\mathrm{Y}}$ with increasing light. This latter phenomenon necessitates the employment of an NPQ correction that deviates from a 1/iPAR relationship.
Normalizing our $F_{\mathrm{Y}}$ data to iPAR and fitting this ratio to a power function at iPAR $>E_{\mathrm{k}-\mathrm{F}}$ gives best-fit exponents for our low- and high-light treatments of $-0.31(95 \% \mathrm{CI}=0.1)$ and $-0.54(95 \% \mathrm{CI}=0.04)$, respectively (Fig. 7). These exponents are significantly different than the exponent of -1 associated with the inverse light function of Behrenfeld et al. (2009). Similarly, we obtain exponents of -0.43 and -0.45 using data from the Laney et al. (2005) study. These findings are consistent with an unquenched PSI contribution to fluorescence that becomes more significant as PSII fluorescence is increasingly quenched via NPQ. Our results further suggest that a variable model for NPQ (e.g. corrections ranging from iPAR ${ }^{-0.3}$ to $\mathrm{iPAR}^{-0.6}$ ) may be more appropriate than the single fixed relationship of Behrenfeld et al. (2009). To put these corrections in perspective, the change in the quantum yield of fluorescence due to iron limitation, the largest nutrient-related signal in global data, is about 4-fold (Behrenfeld et al. 2009). If we apply an $\mathrm{iPAR}^{-0.4}$ correction for NPQ (rather than $\mathrm{iPAR}^{-1}$ ), fluorescence quantum yields change by up to 2-fold (data not shown). While this result illustrates sensitivity to the choice of NPQ correction exponents, it is not yet clear what range of exponent values should be applied to satellite data. As detailed above, instruments that employ long-pass cutoff filters collect a greater fraction of unquenched PSI fluorescence than instruments measuring a narrow spectral band centered around the PSII fluorescence peak (e.g. MODIS). Accordingly, data from narrow-band measurements require an NPQ correction with an exponent closer to -1 than those derived from long-pass instruments. Employing radiometer based measures of $F_{\mathrm{Y}}$ in laboratory studies would help to determine appropriate corrections (Peperzak et al. 2011).

A notable limitation of the current study is its restriction to a single diatom species. Additional work is still needed to evaluate whether our results are broadly applicable or if taxonomic composition is yet another important confounding factor that must be considered when characterizing NPQ effects. In particular, it remains unclear how changes in PSII:PSI associated with variations in the composition of phytoplankton assemblages influence the contribution of PSI to solar-induced fluorescence emissions.

Acknowledgements. We thank T. Westberry for helpful discussions and comments on early versions of this manuscript. Funding was provided by NASA (NNX08AF72G, NNX07AL80G) and NSF, Biological Oceanography (NSFOCE 0726116). We also thank the Howard Hughes Medical Institute and K. G. Ahern for advisory support for U.A.A. 


\section{LITERATURE CITED}

Behrenfeld MJ, Westberry TK, Boss ES, O'Malley RT and others (2009) Satellite-detected fluorescence reveals global physiology of ocean phytoplankton. Biogeosciences 6:779-794

Berman T (1972) Profiles of chlorophyll concentrations by in vivo fluorescence: some limnological applications. Limnol Oceanogr 17:616-618

Cruz S, Serodio J (2008) Relationship of rapid light curves of variable fluorescence to photoacclimation and nonphotochemical quenching in a benthic diatom. Aquat Bot 88:256-264

Cullen JJ, Lewis MR (1995) Biological processes and optical measurements near the sea-surface: some issues relevant to remote-sensing. J Geophys Res 100:13255-13266

D'Asaro EA (2003) Performance of autonomous Lagrangian floats. J Atmos Ocean Technol 20:896-911

Dijkman NA, Kroon BMA (2002) Indications for chlororespiration in relation to light regime in the marine diatom Thalassiosira weissflogii. J Photochem Photobiol B 66: 179-187

> Dimier C, Brunet C, Geider R, Raven J (2009) Growth and photoregulation dynamics of the picoeukaryote Pelagomonas calceolata in fluctuating light. Limnol Oceanogr 54:823-836

Eisenstadt D, Ohad I, Keren N, Kaplan A (2008) Changes in the photosynthetic reaction centre II in the diatom Phaeodactylum tricornutum result in non-photochemical fluorescence quenching. Environ Microbiol 10:1997-2007

Falkowski P, Kiefer DA (1985) Chlorophyll-a fluorescence in phytoplankton: relationship to photosynthesis and biomass. J Plankton Res 7:715-731

Falkowski PG, Dubinsky Z, Wyman K (1985) Growth-irradiance relationships in phytoplankton. Limnol Oceanogr 30:311-321

Franck F, Juneau P, Popovic R (2002) Resolution of the Photosystem I and Photosystem II contributions to chlorophyll fluorescence of intact leaves at room temperature. Biochim Biophys Acta 1556:239-246

> Franck VM, Bruland KW, Hutchins DA, Brzezinski MA (2003) Iron and zinc effects on silicic acid and nitrate uptake kinetics in three high-nutrient, low-chlorophyll (HNLC) regions. Mar Ecol Prog Ser 252:15-33

Goss R, Pinto EA, Wilhelm C, Richter M (2006) The importance of a highly active and $\Delta \mathrm{pH}$-regulated diatoxanthin epoxidase for the regulation of the PSII antenna function in diadinoxanthin cycle containing algae. J Plant Physiol 163:1008-1021

Govindjee (2004) Chlorophyll a fluorescence: a bit of basics and history. In: Papageorgiou GC, Govindjee (eds) Chlorophyll a fluorescence: a signature of photosynthesis, Book 19. Springer, Dordrecht, p 1-42

Grouneva I, Jakob T, Wilhelm C, Goss R (2007) Evidence for the existence of a fast xanthophyll cycle-independent NPQ component in diatoms. Photosynth Res 91:PS1522

Grouneva I, Jakob T, Wilhelm C, Goss R (2008) A new multicomponent NPQ mechanism in the diatom Cyclotella meneghiniana. Plant Cell Physiol 49:1217-1225

> Grouneva I, Jakob T, Wilhelm C, Goss R (2009) The regulation of xanthophyll cycle activity and of non-photochemical fluorescence quenching by two alternative electron flows in the diatoms Phaeodactylum tricornutum and Cyclotella meneghiniana. Biochim Biophys Acta 1787: 929-938
Holt NE, Fleming GR, Niyogi KK (2004) Toward an understanding of the mechanism of nonphotochemical quenching in green plants. Biochemistry 43:8281-8289

Horton P, Hague A (1988) Studies on the induction of chlorophyll fluorescence in isolated barley protoplasts. 4. Resolution of non-photochemical quenching. Biochim Biophys Acta 932:107-115

Jakob T, Goss R, Wilhelm C (2001) Unusual pH-dependence of diadinoxanthin de-epoxidase activation causes chlororespiratory induced accumulation of diatoxanthin in the diatom Phaeodactylum tricornutum. J Plant Physiol 158: 383-390

Jassby AD, Platt T (1976) Mathematical formulation of relationship between photosynthesis and light for phytoplankton. Limnol Oceanogr 21:540-547

Jeffrey SW, Humphrey GF (1975) New spectrophotometric equations for determining chlorophylls $a, b, c_{1}$ and $c_{2}$ in higher plants, algae, and natural phytoplankton. Biochem Physiol Pflanz 167:191-194

> Joly D, Carpentier R (2007) Regulation of energy dissipation in photosystem I by the redox state of the plastoquinone pool. Biochemistry 46:5534-5541

Kiefer DA (1973) Chlorophyll a fluorescence in marine centric diatoms: responses of chloroplasts to light and nutrient stress. Mar Biol 23:39-46

> Kiefer DA, Chamberlin WS, Booth CR (1989) Natural fluorescence of chlorophyll a: relationship to photosynthesis and chlorophyll concentration in the western SouthPacific Gyre. Limnol Oceanogr 34:868-881

$>$ Krause GH, Weis E (1991) Chlorophyll fluorescence and photosynthesis: the basics. Annu Rev Plant Physiol Plant Mol Biol 42:313-349

> Laney SR, Letelier RM, Abbott MR (2005) Parameterizing the natural fluorescence kinetics of Thalassiosira weissflogii. Limnol Oceanogr 50:1499-1510

- Lavaud J, Kroth PG (2006) In diatoms, the transthylakoid proton gradient regulates the photoprotective nonphotochemical fluorescence quenching beyond its control on the xanthophyll cycle. Plant Cell Physiol 47: 1010-1016

Lavaud J, Rousseau B, Etienne AL (2002) In diatoms, a transthylakoid proton gradient alone is not sufficient to induce a non-photochemical fluorescence quenching. FEBS Lett 523:163-166

> Lavaud J, Strzepek RF, Kroth PG (2007) Photoprotection capacity differs among diatoms: possible consequences on the spatial distribution of diatoms related to fluctuations in the underwater light climate. Limnol Oceanogr 52:1188-1194

> Lee HY, Hong YN, Chow WS (2001) Photoinactivation of photosystem II complexes and photoprotection by nonfunctional neighbours in Capsicum annuum L. leaves. Planta 212:332-342

Letelier RM, Abbott MR, Karl DM (1997) Chlorophyll natural fluorescence response to upwelling events in the Southern Ocean. Geophys Res Lett 24:409-412

Lewis MR, Smith JC (1983) A small volume, short-incubation-time method for measurement of photosynthesis as a function of incident irradiance. Mar Ecol Prog Ser 13: 99-102

Miloslavina Y, Grouneva I, Lambrev PH, Lepetit B, Goss R, Wilhelm C, Holzwarth AR (2009) Ultrafast fluorescence study on the location and mechanism of non-photochemical quenching in diatoms. Biochim Biophys Acta 1787: 1189-1197 
Mitchell BG, Kahru M, Wieland J, Stramska M (2003) Determination of spectral absorption coefficients of particles, dissolved material and phytoplankton for discrete water samples. In: Mueller JL, Fargoin GS, McClain CR (eds) Ocean optics protocols for satellite ocean color sensor validation, Vol. 4. NASA/TM-2003-211621/Rev4-Vol4. NASA Goddard Space Flight Center, Greenbelt, MD, p 39-56

Morel A, Prieur L (1977) Analysis of variations in ocean color. Limnol Oceanogr 22:709-722

Morrison JR (2003) In situ determination of the quantum yield of phytoplankton chlorophyll a fluorescence: a simple algorithm, observations, and a model. Limnol Oceanogr 48:618-631

> Neville RA, Gower JFR (1977) Passive remote-sensing of phytoplankton via chlorophyll a fluorescence. J Geophys Res 82:3487-3493

Niyogi KK, Bjorkman O, Grossman AR (1997) Chlamydomonas xanthophyll cycle mutants identified by video imaging of chlorophyll fluorescence quenching. Plant Cell 9:1369-1380

Öquist G, Chow WS, Anderson JM (1992) Photoinhibition of photosynthesis represents a mechanism for the longterm regulation of photosystem-II. Planta 186:450-460

Owens TG (1986) Light-harvesting function in the diatom Phaeodactylum tricornutum. 2. Distribution of excitationenergy between the photosystems. Plant Physiol 80: 739-746

Peperzak L, Timmermans KR, Wernand MR, Oosterhuis S, van der Woerd HJ (2011) A mesocosm tool to optically study phytoplankton dynamics. Limnol Oceanogr Methods 9:232-244

Ragni M, Airs RL, Leonardos N, Geider RJ (2008) Photoinhibition of PSII in Emiliania huxleyi (Haptophyta) under

Editorial responsibility: Matthias Seaman, Oldendorf/Luhe, Germany high light stress: the roles of photoacclimation, photoprotection, and photorepair. J Phycol 44:670-683

Ruban AV, Lavaud J, Rousseau B, Guglielmi G, Horton P, Etienne AL (2004) The super-excess energy dissipation in diatom algae: comparative analysis with higher plants. Photosynth Res 82:165-175

Schallenberg C, Lewis MR, Kelley DE, Cullen JJ (2008) Inferred influence of nutrient availability on the relationship between sun-induced chlorophyll fluorescence and incident irradiance in the Bering Sea. J Geophys Res 113:C07046, doi:10.1029/2007JC004355

> Strzepek RF, Harrison PJ (2004) Photosynthetic architecture differs in coastal and oceanic diatoms. Nature 431: 689-692

> Ting CS, Owens TG (1993) Photochemical and nonphotochemical fluorescence quenching processes in the diatom Phaeodactylum tricornutum. Plant Physiol 101: 1323-1330

Ting CS, Owens TG (1994) The effects of excess irradiance on photosynthesis in the marine diatom Phaeodactylum tricornutum. Plant Physiol 106:763-770

van de Poll WH, Visser RJW, Buma AGJ (2007) Acclimation to a dynamic irradiance regime changes excessive irradiance sensitivity of Emiliania huxleyi and Thalassiosira weissflogii. Limnol Oceanogr 52:1430-1438

van de Poll WH, Buma AGJ, Visser RJW, Janknegt PJ, Villafane VE, Helbling EW (2010) Xanthophyll cycle activity and photosynthesis of Dunaliella tertiolecta (Chlorophyceae) and Thalassiosira weissflogii (Bacillariophyceae) during fluctuating solar radiation. Phycologia 49:249-259

> Westberry TK, Siegel DA (2003) Phytoplankton natural fluorescence variability in the Sargasso Sea. Deep-Sea Res I 50:417-434

Submitted: March 9, 2011; Accepted: December 5, 2011 Proofs received from author(s): February 17, 2012 